\title{
Raising Culture Awareness Using Manga and Harlequin Styled Romance
}

\author{
Gracia SUDARGO \\ Liberal Arts Department \\ Pelita Harapan University \\ Surabaya, Indonesia \\ gracia.sudargo@uph.edu
}

\author{
Karin Lucia TANOJO \\ Psychology Department \\ Pelita Harapan University \\ Surabaya, Indonesia \\ karin.tanojo@uph.edu
}

\begin{abstract}
Republic Indonesia's government policy to issue Porn Laws and really enact them had created mass controversy in the nation. However, flowing streams of porn texts and erotic discourses still flooded the translated literature publishing. Two most demanded and well spread pop literatures are Japanese hentai manga and American Harlequin-styled romance. These two pop literatures provide the two tips of a polar philosophy in defining porn and erotica. Youngsters and university students in Surabaya are quite familiar with these two types, even some in English. Unconsciously youngsters are becoming more unaware and not critical towards pop culture they get exposure on. This philosophical research tries to clarify the perspective from youngsters around Surabaya about erotica and pornography in hentai manga and harlequin-styled romance. Using questionnaire and interviews to triangulate the findings in literature research, it is aimed that the contrasts found in hentai manga and harlequinstyled romance might trigger the redefinition of erotica and pornography. This research tries to teach pop culture awareness using English texts to teen students around Surabaya. Students will see the texts they are often familiar with in new perspective through critical cultural awareness.
\end{abstract}

Keywords - pornography; pop culture; youngsters; cultural awareness

\section{INTRODUCTION}

Pornography is a popular subject under scrutiny these days. There is a raise in juvenile delinquency with pornographic tendency, it alarms many social stakeholders. Although most people might define porn merely as something with vulgar or explicit sexual content, actually porn itself goes beyond such simplification. This calls for debate and intricacy in defining what should be categorized as porn. Reference [1] describes pornography as below: "Pornography is a term in popular use but can also be a legal term. For the purposes of simplicity in the present discussion, pornography is broadly defined as any sexually explicit material primarily developed or produced to arouse sexual interest or provide erotic pleasure. It can be so-called soft-core or hard-core and it can extend from pin-ups which might be offensive to XXX fetish or materials involving children (socalled 'child-porn')."

Another controversial definition comes from Planned Legislature of Republic Indonesia Regarding Pornography in
Chapter (Undang-Undang Pornografi tahun 2008) "Pornography is sexual material that is made by humans by form of picture, sketch, illustration, photo, writings, vocalizations, sounds, moving picture, animations, cartoon, rhymes/poems/prose/verse, lewd sexual gestures (straddling, blowing kisses, miming oral sex), eurhythmics or lewdness deliberately disguised as double entrendre communications [simulated sexual acts] - communicated or transmitted via media communications and/ or public shows/ exhibits/ performances [implied: live] that arouses sexual propensities/desires/longings [implied: undesirable] and/or contravenes community ethics/decency/ morality [one word: kesusilaan]."

Thus, it can be said that pornography is build simply to arouse sexual desire. A text can be categorized as porn when it is capable of arousing sexual desire. However, the further discussion actually talks about how "arousing sexual desire" should be defined? This research tries to present indicators on desire arousal.

\section{THEORETICAL REVIEW}

\section{A. Hentai}

Book is a popular product, yet its influence is not always admitted. Books are often perceived as the source of knowledge, but just like a double bladed weapon, books can also bring destruction. In market itself, there are lots of books containing pornography, yet people do not really understand it and consider them as popular readings. One of the most popular texts among youngsters is Hentai. The term Hentai in Japanese language actually means pervert or sexually abnormal. Japanese Dictionary translates hentai into three meanings; the shift of shape, shortened version of hentai seiyoku, and metamorphosis.

It is interesting to know that even though Hentai had become a superb representative characterizing Japanese literature; this category has never been discussed in the English studies of manga and anime. Perhaps it is because of Hentai's absurdity and sexually offensiveness, but perhaps also due to the lack of understanding towards its significance of the realm of world literature. For centuries, in the world of English Literature, pornographic and erotic texts had never been granted as serious literary production, yet they have 
always become the most well spread and consumed readings. Despite its status as illegal and unacceptable in many regions of human habitats, still pornographic and erotic texts can be found in almost every civilization and culture around the world.

Since Meiji era, the term hentai had been used in science and psychology. However, it refers to abnormality later in Meiji era to defined disorders such as hysteria, telepathy, or hypnosis. In other words, Hentai has been commonly used to refer Japanese-culture based erotic text serving explicit and abnormal sexual activity to arouse readers' sexual desire. Therefore, Hentai is no longer abnormal pornography served limitedly only for certain groups of sexual disorders, but also become a massive public consumption.

\section{B. Harlequin}

On the other hand, another group of media with lower perception as porn is Harlequin. Harlequin was not a common term for calling a subgenre. It was the name of a Canadian publisher for paperback romance fiction. Harlequin publisher was founded on 1949, at the edge of a new era. Before 1949, issues on feminism were just a mere whisper, almost unheard, in the streams of literature thoughts. Virginia Woolf had been known as one of prominent feminist writer, yet the noise of $1^{\text {st }}$ and $2^{\text {nd }}$ World War distracted our attention to other matters such as humanities, technology, and poverty. However, at the same year when Harlequin was founded, a signal for the new era in literature was bursting. A French feminist named Simone de Beavoir wrote that western civilization had always been unfair in their patriarchal system by defining what it meant to be human only from male point of view. Beavoir called for women all around the world to reject being marked as the 'other', and strive for women's rights to be autonomous. This caught the world's eyes on feminist issues.

Harlequin executive decision put its publishing lines focusing on romance genre set in North America. Readers without scholar background would chew these paperbacks while sitting in front of fire-hearth, cuddling on bed, snacking on couch, and even sipping coffee on streets. They did not need to attain any prestigious background knowledge to be able to enjoy Harlequin's products. As a result, Harlequin had become the leading publisher in romance fiction. Unfortunately, most material components in Harlequin subgenre is not entirely free of pornographic elements. Even, some of them are quite explicit in eliciting erotic scenes.

Based on the explanation above, this research aims to get a glance at youngsters' perception towards 'hentai' and 'harlequin'. Youngsters are fragile age-groups, they could easily accept values and aspects in these two literary texts. Thus, researcher conducts this research to understand how these groups respond towards Hentai and Harlequin.

\section{PROBLEM Formulation AND METHODOLOGY}

This research focuses on understanding youngsters' perception towards pornographic aspects in Hentai and Harlequin sub-genre. The object of this research is 12-25 year old youngsters. Some questions to ponder in this research are:
1. What are the aspects of porn in 'Hentai' and 'Harlequin'?

2. How do these aspects differ in 'Hentai' and 'Harlequin?'

This research uses mixed method, both quantitative and qualitative, to analyze the data gathered in order to understand the youngsters' perception towards pornographic aspects in Hentai and Harlequin. Research procedure results in descriptive data, which can be oral or written from both human and observable behavior, should be directed towards holistic background and individual. Therefore, we should not isolate certain individual or organizational in certain variable or hypotheses, but we need to see it as a part of wholeness. At last, we can understand the phenomenon experienced by participants, such as behavior, respond, motivation, actions, etc, holistically and in such a description in words and language, within a specified natural context by using natural methods. The qualitative research employs researchers themselves, while quantitative research uses questionnaire. Data gathered using observation, interview, documentation, and questionnaire distribution.

\section{RESUlTS AND DisCUSSIONS}

There are many categories within the framework of abnormal sexuality. American Psychiatric Association (APA) in their Diagnostic and Statistical Manual of Metal Disorders (DSM-IV TM) mentions three categories under the roof of sexual disorders and problems; they are sexual dysfunction, gender identity disorders, and paraphilias. Sexual dysfunction is "disruptions in sexual functioning found in people who are otherwise good psychological health." Gender identity disorders are used to describe people who think they are of the opposite sex. It is interesting that ref [2] relates sexual dysfunction and gender identity disorders closely. A man who thinks that he is actually a woman will have disruptions in his sexual functions when he is having sexual stimuli from the opposite sex. The third category is the most interesting one. Paraphilia comes from two words, philia means strongly attracted to or like, while para indicates that the liking is abnormal.(Durand, 2006) Paraphilia consist of many different subcategories, and it is interesting that Hentai provides such a wide range of abnormal sexual displays as if they only a matter of appetite.

DSM-IV TM states that paraphilia should be differentiated from the earliest aspect of sexual arousal; "the use of sexual fantasies, behaviors, or stimulus for sexual excitement.' Hentai functions as provider for such stimulus, if someone browse freely for Hentai, it is easy to get a full menu with many options of paraphilia categories. According to DSM-IV TR, there is a category called exhibitionism which exposes someone's genitals to strangers, usually it includes sexual activity either masturbation or intercourse. Another category is called fetishism that is using unanimated objects (for example women's underwear, stocking, or other wearing appeal) as the stimulus. The third category mentioned by DSM-IV TR is frotteurism that involves touching and 
rubbing against a non-consenting person. This category served a common term in Hentai named groping. Groping in Hentai is usually happened in crowded public places, the most popular scene is on train or in a station. The fourth category is pedophilia. Although some Hentai texts do not explicitly mention the age of the character, but the way they display physical characteristic of the female victim suggest a young age. Things like small undeveloped breast, clear naïve eyes, school uniform, and high-pitched voice would constantly create an imagery of female character under the consenting age. The fifth and the sixth categories are inter-related to each other, they are sexual masochism and sexual sadism. There is a widespread category of Hentai called BDSM abbreviated from Bondage and Discipline, Domination and Submission, Sadism and Masochism. It involves many methods of causing pain such as spanking, being tied up, beating, etc. The only purpose both from the one conducting the act of causing pain and the one receiving pain is to get aroused sexually, 'to derive sexual excitement from the psychological or physical suffering.' The seventh category mentioned is transvestic fetishism. Usually a person with this abnormal sexuality will wear the opposite sex's dressing and masturbate while imagining that $\mathrm{s} /$ he becomes both the male and female subject. Cross dressing is not quite popular in Hentai because Japanese culture provides a more subtle imagery from its mythical character called futanari. Futanari is a depiction of hermaphrodite or transsexual, it could be a woman body with breast but has male penis and scrotum, or have both phallic genitalia (penis with scrotum, only a penile shaft, or an enlarged clitoris) and vaginal genitalia. The last category mentioned is voyeurism that is the act of 'observing an unsuspecting individual undressing or naked to become aroused [2].' Video production from hidden camera in shop's dressing room is a trending phenomenon in Hentai categorization.

Other sexual abnormalities which do not meet the requirement produced by DSM-IV TR to be categorized are place in a category of paraphilia not otherwise specified. Some examples given in it is telephone scatologia (phones sex), necrophilia, and partialism (exclusive focus on part of body). However, DSM-IV TR does not mention homosexuality as a category of abnormal sexuality. Actually APA stopped mentioning homosexuals as abnormal in their DSM productions more as a political decision rather than an academic decision. In 1973, National Gay Task Force suppressed APA to declare that homosexuality will no longer be considered as abnormality. Before 1973, in DSM I and DSM II, homosexuality is an abnormality. Actually hundreds of APA members disagreed with this change. Thus, a voting needed to be held. Before the voting began, a letter signed by three medical doctors competing for the presidential chair of APA was distributing to all members. This letter strongly insisted the APA members to agree on the shift. Therefore, on DSM III, homosexuality is not mentioned as abnormal sexuality.

As a product of economy instead of literature, Harlequinstyled romance focuses on what the market wants, not what the literary standard says. This subgenre employs some special attributes to characterize its identity among other romance publications. These attributes are involved in a writing technique called sweet writing. Although different lines in Harlequins' might focus on different aspects, but some basic ingredients are constantly a must for the recipe. Basically, Harlequin romance provides a catharsis escape for the readers by allowing them to re-identify themselves as the heroine in the story. In order to do this, the setting of the story might be extremely various. Harlequin addresses for 'real-world contemporary issues' surrounding and contributing to 'the lives and loves of modern men and women'. As long as emotion becomes the solid foundation for conflict, almost any story can fit [3].

Feminism issues criticize the way patriarchal society put ethic codes on what is meant to be a man, to be a woman, to be a human being, taken only from the point of view of the ruling sex; the male dominance. By having such a large criteria and description of what a heroine should look like, Harlequin is actually declaring to the world that none can really define the ethic codes for becoming a woman [4]. It is okay to be a soft hearted virgin with brunette hair and pale skin, just as it is okay to be a broad tattooed black-skinned assassin. A heroine might be working as a nude model or a house wife; there is no single definition on who women are and what role they might play in the society.

As it is mentioned before, this subgenre is not a pure production for the sake of literature; it is more an economic production to satisfy consumer's appetite. More than $80 \%$ of the Harlequin readers are women. Thus, the stories are told from the women's point of view, either the first singular person or the third all-knowing point of view. This kind of story telling enables the readers, who most of them are women, not only feel engaged with the emotion roller coaster on the plot, but also to identify themselves as the heroine in the story, and therefore to 'steal' the characters' emotion and feelings. The main course of this subgenre is having two persons, a man and a woman, building romantic love relationship while having the entire world of readers savoring every detail of their intimacy and sexuality. Then, what would be the benefit if the readers? What goal do they want to achieve by taking over a fictional emotion and identity in a romantic pursue?

"Sweet readers want to be emotionally aroused above all else. For me, the best kind of emotion comes from simple, realistic conflicts that make you bleed inside rather than from overly complicated melodrama. Having your characters wave their arms around and make much ado about nothing is not a convincing substitute for true emotional punch [2]."

'Sweet readers' which consist mostly of women are aroused in a different way from men. While pornography laws focus their definition of 'porn' on the erotic sexual arousal, according to ref [5], sexual arousal itself is a system of overlapping and complex order. 
"Sexual arousal is a complex state that involves: (i) information processing of sexual stimuli, involving both automatic (or unconscious) and conscious cognitive mechanisms; (ii) incentive motivation, which includes activation of the dopaminergic incentive motivational system involved in a variety of appetitive behaviors; (iii) general arousal, or activation of the central arousal system involved in most arousal states (e.g., pleasurable excitement, fear or sexual excitement); and (iv) genital response. It is the "genital response" that is the most specifically sexual component of this state although, in the relevant context, the information processing will be focused on sexual stimuli."

It is widely believed among scholars of sexuality that man and woman are different in distinguishing sexual desire and sexual arousal. For man, sexual desire is the only the first two steps in Bancroft's sexual arousal stages; that is information processing of stimuli and incentive motivation. Man tends to categorize himself to be sexually aroused when he has reached the fourth stage; that is genital response. On the other hand, for woman, sexual desire is often overlapped with sexual arousal. In fact, woman is more 'responsive' and 'triggered' rather than having 'spontaneous' arousal as in man [5].

A man might be sexually aroused spontaneously at the moment he gets some sexual stimuli such as a woman displaying most of her private body parts, or watching a sexual activity performed on screen. Yet a woman would prefer to be aroused through a series of sexual triggered involving stimuli and some motivation for her appetitive behaviors. Women often get engaged in sexual activity not because of her own intrinsic sexual desire, rather from a state called "sexual neutrality," a stimuli primarily motivated by non-sexual reasons, such as desire for emotional closeness with a partner. Thus, in Harlequin, sexual activities are not always explicitly being involved, instead, sexual relationship is being described in such a way that the readers will feel intimate and get engaged first with the characters. Sexual activities might be explored whenever needed in the plot to support the conflict development. Once the readers had been closely intimate with the emotion presented in the story, the first stage of sexual arousal is begun.
[4] C. Bressler, Literary criticism, New Jersey: Prentice Hall, 1999.

[5] Bancroft, J. and C.A. Graham, "The varied nature of women's sexuality: unresolved issues and a theoretical approach", Hormones and Behavior, Volume 59, Issue 5, May 2011, p. 717-729. Available online at http://www.sciencedirect.com.pustaka.ubaya.ac.id/science/article/pii/ S0018506X11000079. Retrieved on 1 June 2011.

\section{References}

[1] M. Diamond, "The effects of pornography: an international perspective. porn 101: eroticism, pornography, and the first amendment", 1999, p. 223-260. Available online http://www.hawaii.edu/PCSS/biblio/articles/1961to1999/1999-effectsof-pornography.html. Retrieved on 8 June 2011.

[2] V. Durand, Mark and H.B. David, "Essentials of abnormal psychology"(fourth edition), Belmont: Thomson Wadsworth, 2006.

[3] N. Logan, "Subgenre in focus: harlequin romance (sweet)", 2010. Available online at http://www.nikkilogan.com.au/writingsweet.pdf. Retrieved on 13 May 2011. 